\section{Why old fiddles sound sweeter}

SIR - Musicians often claim that regular playing of a stringed instrument improves its tone ${ }^{1}$. Although sound quality is subjective, it is often thought desirable to have high stiffness-to-weight ratio and low damping coefficient ${ }^{2-4}$, as are found in the mature pine and spruce commonly used for sounding membranes. Here we show that for spruce, at higher humidities, continuous forced vibrations cause the stiffness to increase and the damping coefficient to decrease, thus lending support to the musicians' claim. The changes are ascribed to slow redistribution of moisture to lower-energy sites.

We subjected beams of spruce $(85 \times 12$ $\times 0.5 \mathrm{~mm}$ ) to continuous vibrations at the natural frequency of $10 \mathrm{~Hz}$ (see figure). The damping coefficient was found to drift downwards by about $5 \%$ on average, sometimes after an initial small increase. When the forced vibrations ceased, there was little change. The forced vibrations always caused an increase in the natural frequency of about $0.3 \%$. At $44 \%$ relative humidity $(\mathrm{RH})$, the forced vibrations showed little effect considering the precision of the experiment.

The damping coefficient of wood is higher at higher humidities, with typically a $3.5 \%$ increase in damping coefficient for each $1 \%$ rise in wood moisture content. Measurements during continuous vibrations with simultaneous step-humidification from $80 \%$ to $90 \%$ RH showed a very rapid increase in damping coefficient followed by a slight drift downwards. The increase was more rapid with forced vibrations than without, typical time constants for the same test piece being approximately halved by the forced vibrations (for example, $0.4-0.15 \mathrm{~h}$ ). The time constant for the moisture content increase of a matched weighed sample was typically $3 \mathrm{~h}$.

The explanations for the various anomalies observed may lie with the mechanisms of moisture bonding. On the basis of sorption isotherms, Kollmann ${ }^{5}$ suggested that sorbed water could be divided into three groups: monolayer adsorption at low humidities, multilayer adsorption starting at intermediate humidities, and relatively free capillary water, which predominates at higher humidities below the fibre-saturation point. The rapid increase in damping during humidification may result from the breaking of bonds by internal swelling strains. The effect of

1. Bond, C. J. Inst. Wood Sci. 7, 30-33 (1977).

. Carrington, J. J. Inst. Wood Sci. 7, 10-14 (1976).

3. Fukada, E. Nature 161, 772-773 (1950).

4. Holz, D. Holztechnologie 4, 195-202 (1973)

5. Kollmann, F. Forsch. Gebiete Ingenieurw. 29, 33-41 (1963).

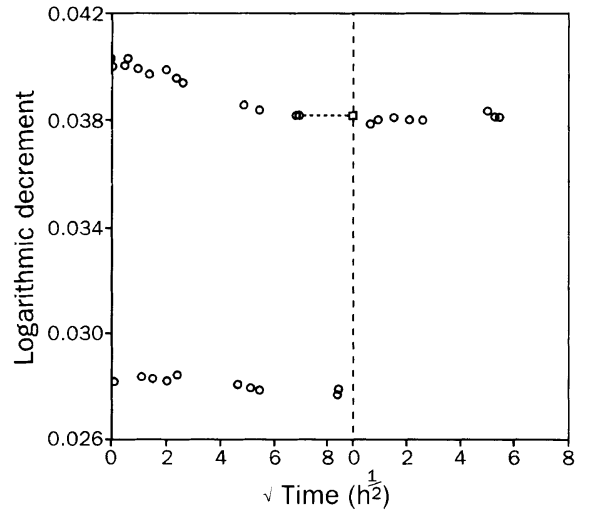

Damping coefficient expressed as logarithmic decrement plotted against the square root of time during forced vibrations at the natural frequency of a spruce cantilever beam of dimensions $85 \mathrm{~mm}$ (axial) by $12 \mathrm{~mm}$ (radial) by $0.5 \mathrm{~mm}$ (tangential), at $90 \% \mathrm{RH}$ (upper) and $44 \% \mathrm{RH}$ (lower). The vibrations were switched off after $48 \mathrm{~h}$. Left, with vibrations; right, vibrations stopped. Measurements were made following moisture equilibration (to an estimated tolerance of $0.3 \%$ ). The time at equilibrium humidity was at least 16 times the measured sorption time constant. At $90 \% \mathrm{RH}$, the experiment was continued by switching off the vibrations after $48 \mathrm{~h}$. The coefficient of variation of the measurement technique was $0.35 \%$ for the damping coefficient and $0.0065 \%$ for the frequency. The humidity of the environmental chamber was maintained within $\pm 1 \% \mathrm{RH}$ and $\pm 0.1^{\circ} \mathrm{C}$. The measurements made during continuous forced vibrations at constant humidity were made six times, on matched samples.

the simultaneous forced vibrations may be to raise the energy levels at many of the bonding sites and so accelerate the bond-breaking process that must accompany the moisture-induced swelling.

The slow decrease in damping and increase in stiffness during vibrations at constant high humidity may be the result of slow re-location of water molecules from high-strain, and therefore high-energy, sites, to lower-energy sites. The fact that little change takes place at $44 \% \mathrm{RH}$ suggests that it is mainly the multilayer water molecules that are re-located. It was found that the changes could be reversed by drying the samples at $30 \% \mathrm{RH}$ and then re-humidifying.

Although, for the best care of a musical instrument, both high and low humidities should be avoided, the above results suggest that at intermediate or high humidities the sound quality may be improved by regular playing.

\section{G. Hunt, E. Balsan}

School of Engineering Systems and Design,

South Bank University,

London SE1 OAA, UK
Similar bacteria in remote oil fields

SIR - LHaridon et al. recently reported the isolation of thermophilic microorganisms from oil wells ${ }^{1}$. Besides 'marine' hyperthermophilic Archaea, they have isolated several bacterial strains that can be ascribed to the Thermotoga, Thermoanaerobacter or Thermodesulfobacterium genera. This bacterial flora is very similar to that isolated from another oil well, located in the Paris Basin ${ }^{2,3}$. That well had similar depth, pressure, temperature and water salinity characteristics.

Very closely related bacteria were also isolated from oil wells located thousands of kilometres apart. Thermotoga elfii ${ }^{4}$, isolated from an oil well in the Cameroons, and Thermotoga subterranea, described by L'Haridon et al. ${ }^{1}$ and Jeanthon et al. ${ }^{5}$, may well represent the same species. They display the same morphological, physiological and metabolic characteristics, and share $98.2 \%$ of their $16 \mathrm{~S}$ ribosomal RNA sequence. T. elfii with similar characteristics has also been isolated from several other oil fields (my unpublished data). These geographically remote oil fields constitute geologically isolated and physicochemically peculiar ecosystems. Considering the close physiological adaptation of the bacteria to their habitat ${ }^{2}$, they are unlikely to have been accidentally introduced into the oil fields during recent drilling operations, with well equipment or in subsequent production operations. All these observations strengthen the hypothesis that these microorganisms are indigenous $s^{1,2}$.

Several important questions remain. For example, where are these bacteria from? How did they succeed in colonizing these habitats? Note that Thermotoga, as well as other mesophilic anaerobes we have isolated from various oil fields (manuscript in preparation), represent the most ancestral branches of the bacteria. Are these microorganisms directly descended from bacteria that were trapped during the formation of the oil, or accompanied its migration through tens to hundreds of millions of years? Did they arrive in the oil field later as a consequence of aquifer activity? What is their mode of maintenance and development in their environment? Much work is needed to answer these questions. Michel Magot

Sanofi Recherche,

Elf Aquitaine Group, Microbiology Unit, F-31676 Labège, France

1. L'Haridon, S., Reysenbach, A.-L., Glénat, P., Prieur, D. \& Jeanthon, C. Nature 377, 223-224 (1995).

2. Bernard, F. Connan, J. \& Magot, M. Proc 67th SPE a. tech. Conf. Exhibition Vol. 2, 467-476 (SPE, Dallas, TX 1992).

3. Cayol, J.-L. et al. Int. J. syst. Bact. 45, 783-789 (1995).

4. Ravot, G. et al. Int. J. syst. Bact. 45, 308-314 (1995).

5. Jeanthon, C. et al. Archs Microbiol. 164, 91-97 (1995). 